\title{
Solvothermal synthesis and characterization of hierarchical spindle-like $\mathrm{BiPO}_{4}$ aggregates
}

\author{
Ming $\mathrm{Ou}^{1}$, Lin Ma ${ }^{1, a}$, Limei $X u^{1}$, Haizhen $\mathrm{Li}^{1}$, Zhuomei Yang ${ }^{1}$ and Zhifeng Lan ${ }^{1}$ \\ ${ }^{1}$ School of Chemistry and Chemical Engineering, Institute of Physical Chemistry, Lingnan Normal University, \\ Zhanjiang 524048, P. R. China
}

\begin{abstract}
Monodispersed spindle-like $\mathrm{BiPO}_{4}$ aggregates with uniform morphology and size were prepared by a solvothermal route with ethylene glycol (EG)/water as mixed solvent, bismuth nitrate and sodium tripolyphosphate (STPP) as raw materials. The products were characterized by X-ray powder diffraction (XRD), scanning electron microscopy (SEM) and UV-vis absorption spectroscopy. The results indicate that obtained BiPO4 products are hexagonal phase and have good crystallinity and high purity. Additionally, it is found that the both STPP and mixed solvent play a crucial role in the formation of the spindle-like $\mathrm{BiPO}_{4}$ aggregates, which are constructed through oriented aggregation of nanoparticles. The possible formation process was initially presented. Moreover, the bandgap energy of these novel spindle-like $\mathrm{BiPO}_{4}$ aggregates is also estimated as $3.46 \mathrm{eV}$ from the UV-vis absorption spectrum.
\end{abstract}

\section{Introduction}

Inorganic nanomaterials with controllable size and shape have been one of the hottest research fields based on the supposition that there is a strong correlation between these parameters and their properties and potential applications [1]. Specially, hierarchical micro/nanostructures, which are assembled from nanoparticles, nanorods or nanowires, and nanosheets or nanoplates as building blocks, have recently attracted significant attention. It is believed that the hierarchical structures can inherit the unique advantages of their pristine building blocks and obtain intriguing properties from their superior secondary architecture [2]. To date, various compouds with hierarchical micro/nanostructures have been successfully prepared and exhibited novel photo/electrochemical properties and a wide spectrum of potential applications [3-6] .

As one kind of important bismuth-containing oxysalts, bismuth phosphate $\left(\mathrm{BiPO}_{4}\right)$ is a typical compound that crystallizes in two polymorphs such as hexagonal phase and monoclinic phase, which have found potential applications in catalysis, sensors, and many other functional materials for separating radioactive elements [7-9]. In addition, $\mathrm{BiPO}_{4}$ was reported to be an excellent host for rare-earth ions that can yield luminescence and a novel photocatalyst for degrading organic dyes [7, 10]. $\mathrm{Up}$ to now, $\mathrm{BiPO}_{4}$ micro/nanomaterials with different morphologies have been synthesized such as nanoparticles [11, 12], nanorods [13-18] and hierarchical architectures $[19, \quad 20]$. To obtain such micro/nanomaterials, a variety of methods including chemical vapor deposition21, sonochemical method [13, 22], microwave irradiation [19], electrochemical deposition [15], hydrothermal/solvothermal treatment [14, $18,23,24]$ have been employed. In spite of a few approaches developed to fabricate $\mathrm{BiPO}_{4}$ hierarchical

\footnotetext{
a Corresponding author: ml_buct@126.com
}

micro/nanostructures, which followed complicated and tedious experimental procedure and might cause pollution, a facile synthesis of $\mathrm{BiPO}_{4}$ hierarchical architectures is still an ongoing challenge.

In this paper, we report a facile solvothermal method to prepare spindle-like $\mathrm{BiPO}_{4}$ hierarchical aggregates with sodium tripolyphosphate (STPP) and bismuth nitrate as reactants and ethylene glycol (EG)/water as solvent. It is found that the as-prepared $\mathrm{BiPO}_{4}$ microspindles are assembled by numerous nanoparticles in an oriented way and both STPP and the volume ratio of EG to water have great influences on the morphology of the final product.

\section{Experimental procedure}

\subsection{STPP-assisted synthesis of BiPO4 spindle-like aggregates}

The experimental procedure was designed as follows. $1 \mathrm{mmol}$ of $\mathrm{Bi}\left(\mathrm{NO}_{3}\right)_{3} \cdot 5 \mathrm{H}_{2} \mathrm{O}$ was dissolved in $15 \mathrm{ml}$ ethylene glycol to form a solution A and $1 \mathrm{mmol}$ of STPP $\left(\mathrm{Na}_{5} \mathrm{P}_{3} \mathrm{O}_{10}\right)$ was dissolved in $45 \mathrm{ml}$ deionized water to form a solution $\mathrm{B}$. Then the solution $\mathrm{B}$ was slowly dropped into the solution $\mathrm{A}$ under vigorous stirring to form a mixture. After stirring about $30 \mathrm{~min}$, the mixture was finally transferred into a $100 \mathrm{ml}$ Teflon-lined stainless steel autoclave. It was sealed tightly and maintained at $150{ }^{\circ} \mathrm{C}$ for $12 \mathrm{~h}$. After that, the autoclave was allowed to cool down naturally. The products were collected, and washed three times using deionized water and absolute ethanol, then dried for $12 \mathrm{~h}$ under vacuum at $60{ }^{\circ} \mathrm{C}$. 


\subsection{Characterization of $\mathrm{BiPO}_{4}$ samples}

XRD analysis was performed on a D/Max-2550 X-ray diffractometer with monochromatized $\mathrm{CuK}$ a radiation ( $\lambda=0.1540562 \mathrm{~nm}$ ). SEM images were taken with FEI SIRION-100 field-emission scanning electron microscope. Absorption spectrum was measured on a UV-vis spectrophotometer (UV-2550) in the wavelength range of $200-700 \mathrm{~nm}$.

\section{Results and discussions}

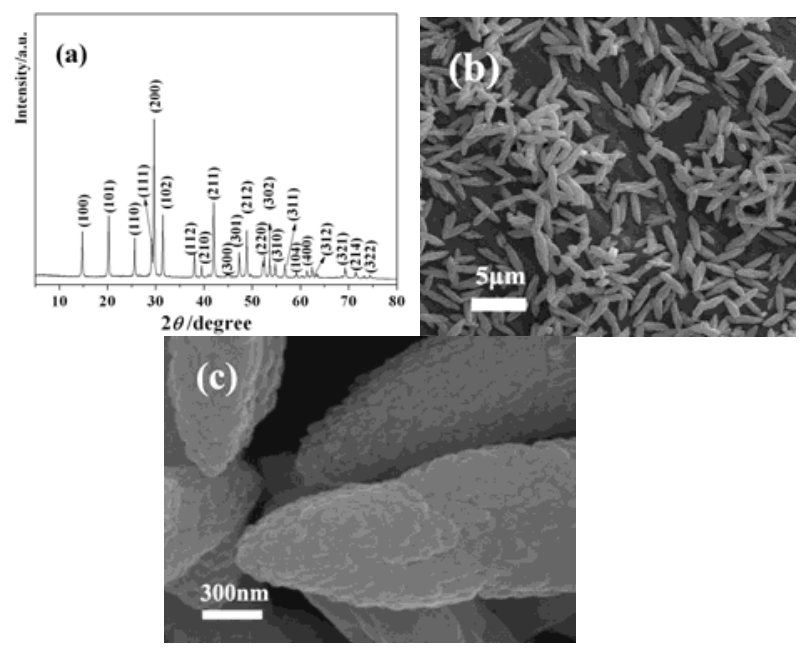

Figure 1. XRD patterns and SEM images of $\mathrm{BiPO}_{4}$ spindle-like aggregates prepared by a STPP-assisted solvothermal route.

The crystal structure and phase purity of the products are determined by XRD. A typical XRD pattern of the $\mathrm{BiPO}_{4}$ microspindles is presented in Fig. 1a. The major detectable diffraction peaks can be readily indexed to the hexagonal phase of $\mathrm{BiPO}_{4}$ consistent with the standard powder diffraction file of $\mathrm{BiPO}_{4}$ (JCPDS 15-0766). No impurity phase can be found. The high and sharp peaks are indicative of good crystallinity in spite of slightly broadened diffraction peaks. The XRD result confirms that the well-crystallized hexagonal $\mathrm{BiPO}_{4}$ products can be easily prepared in our synthetic strategy. The morphology and microstructure details of the $\mathrm{BiPO}_{4}$ products were investigated with SEM. Fig. $1 \mathrm{~b}$ shows a typical SEM image to exhibit the overall view of the $\mathrm{BiPO}_{4}$ products, clearly demonstrating a well-dispersed distribution of spindle-like rods with uniform morphology and size. It is estimated that the microspindles of a mean length about $3.15 \mu \mathrm{m}$ and a middle width about $790 \mathrm{~nm}$ have an aspect ratio approaching $4: 1$, and that a high yield close to $100 \%$. Fig. 1c clearly reveals surface structures of these microspindles, from which it can be seen that the surfaces are rather rough and numerous flat nanoparticles with size of $70 \mathrm{~nm}$ orientedly arrange on the surface. Therefore, it is reasonable to speculate that these novel microspindles with hierarchical structures should be assembled by many nanoparticles through an oriented aggregation.

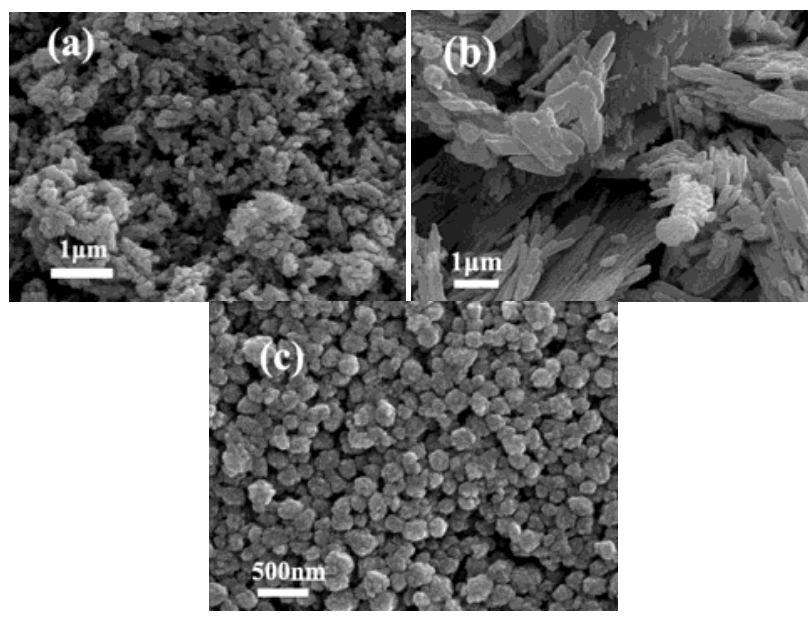

Figure 2. SEM images of $\mathrm{BiPO}_{4}$ products prepared (a) with $\mathrm{Na}_{2} \mathrm{HPO}_{4}$ as reactant; (b) with water as solvent and (c) with EG as solvent.

It can be seen from Fig. 2a that the obtained $\mathrm{BiPO}_{4}$ products are scattered irregular particles when STPP is replaced by equivalent amount of $\mathrm{Na}_{2} \mathrm{HPO}_{4}$. This result explicitly indicates that STPP plays a crucial role in the formation $\mathrm{BiPO}_{4}$ spindle-like aggregates. In addition, in order to investigate the effect of solvent, the $\mathrm{BiPO}_{4}$ products were also prepared by a similar process with pure water and pure EG as solvent, respectively. Fig. $2 \mathrm{~b}$ manifests that the $\mathrm{BiPO}_{4}$ products obtained with water as solvent are microspindles with ununiform morphology and size. Moreover, these spindles are interconnected side by side. With EG as solvent, the products are uniform spheres assemble by nanoparticles. The above control experiment results demonstrate that an appropriate ratio of EG to water also acts as a key factor to obtain spindle-like $\mathrm{BiPO}_{4}$ aggregates.

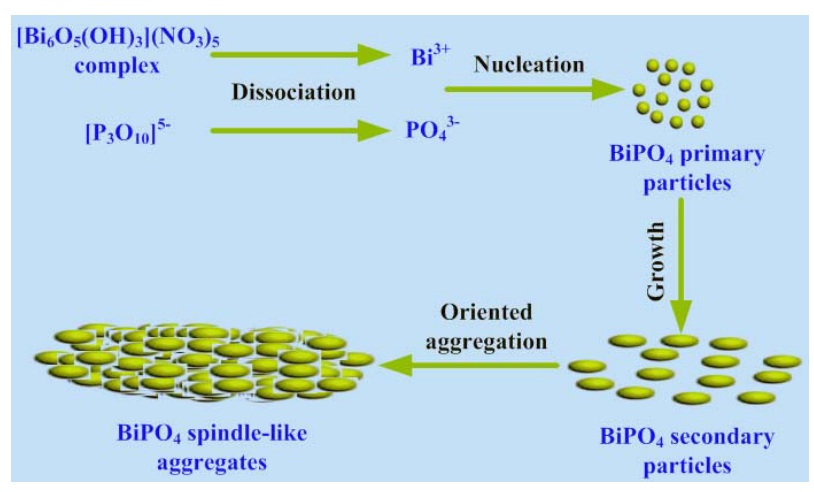

Figure 3. Illustration of the formation process of the spindlelike $\mathrm{BiPO}_{4}$ aggregates.

Based on the experimental results, the probable formation mechanism of the spindle-like $\mathrm{BiPO}_{4}$ aggregates may be ascribed to an oriented aggregation process in our current experiment. First, $\mathrm{Bi}\left(\mathrm{NO}_{3}\right)_{3}$ could alcoholyze and hydrolyze in EG and water to form a bismuth oxide hydroxide nitrate complex which might be in the form of $\left[\mathrm{Bi}_{6} \mathrm{O}_{5}(\mathrm{OH})_{3}\right]\left(\mathrm{NO}_{3}\right)_{5}$ and then $\mathrm{Bi}^{3+}$ was generated at a release speed by the dissociation of the complex [14, 19]. Meanwhile, $\mathrm{PO}_{4}^{3-}$ ions were also provided by gradual dissociation of STPP in EG/water system. Subsequently, $\mathrm{PO}_{4}^{3-}$ combined with $\mathrm{Bi}^{3+}$ to form $\mathrm{BiPO}_{4}$ primary 
nanoparticles and would further grow into flat secondary particles due to the capping effect of EG. EG-water system with proper volume ratio could not only guarantee an opportune nucleation rate but also have appropriate viscosity that allowed the $\mathrm{BiPO}_{4}$ secondary particles to find suitable low-energy configuration interfaces and thus aggregated in an oriented way to form the final microspindles. The detailed formation mechanism deserves further investigations. The schematic illustration for the formation of the spindle-like aggregates is shown in Fig. 3

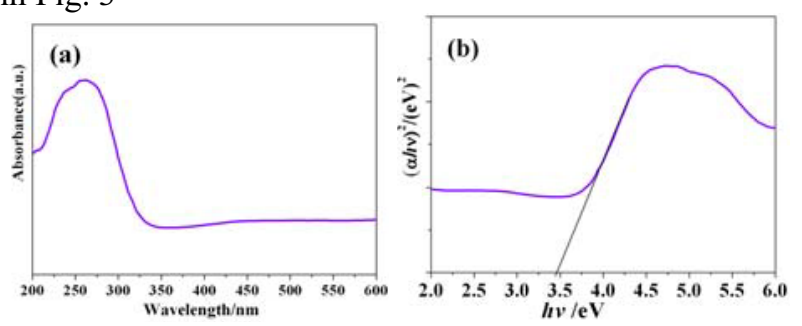

Figure 4. UV-vis absorption spectrum of the spindle-like $\mathrm{BiPO}_{4}$ aggregates.

Fig. 4 shows the UV-vis absorption spectrum of the spindle-like $\mathrm{BiPO}_{4}$ aggregates, which displays the photoabsorption property from the UV light region. The steep shape of the spectrum indicates that the UV-light absorption was due to the band gap transition. As a crystalline semiconductor, the optical aborption near the band edge is based on the equation $\alpha h v=A(h v-$ $\mathrm{Eg})^{1 / 2}$ (where $\alpha$ is the absorption coefficient, $\mathrm{A}$ is a constant, $h v$ is the photo energy, and Eg is the bandgap energy). From the curve of the $(\alpha h v)^{2}$ vs. photo energy $(\mathrm{hv})$, the bandgap energy of the spindle-like $\mathrm{BiPO}_{4}$ aggregates is estimated to be $3.46 \mathrm{eV}$, slightly lower than or similar to those of $\mathrm{BiPO}_{4}$ materials reported previously [13-20].

\section{Conclusions}

In summary, well-dispersed hexagonal spindle-like $\mathrm{BiPO}_{4}$ aggregates with uniform morphology and size were fabricated by a facile solvothermal process in EG/water solvent. The STPP and mixed solvent play a key role in the formation of spindle-like $\mathrm{BiPO}_{4}$ aggregates, which are assembled by oriented aggregation of nanoparticles. The strategy presented in this work is easily controllable and well reproducible and may be feasible to develop into the scale-up production.

\section{Acknowledgement}

This work is financially supported by the Guangdong Natural Science Foundation for Joint Training Innovative Talents in East-West-North Guangdong (2014A030307030, 2016A030307654), the Science and Technology Planning Project of Guangdong Province (2014A010106032), the Stong Innovation School of Engineering Program of Department of Education of Guangdong Province (Distinctive Innovation Project No. 2014KTSCX157), Natural Science Foundation of Lingnan Normal University (LZL1402, LZL1502).

\section{References}

1. Y. Wang, Y. Xia, Adv. Mater. 25, 5336 (2013).

2. H.B. Yao, H.Y. Fang, X. H. Wang, S. H.Yu. Chem. Soc. Rev. 40, 3764 (2011).

3. H. Zhou, H. Zhang, Y. Wang, Y. Miao, L. Gu, Z. Jiao. J. Colloid. Interface. Sci. 448, 367 (2015).

4. X. Y. Liu, W. G. Bian, C. Y. Tian. Mater. Lett. 112, 1 (2013).

5. M.Y. Li, F.P. Wang, Z. Y. Wang, M. Z. Iqbal, Q. U. A. Javed, Y. Z. Lu, M. Xu, Q. S. Li. Mater. Lett. 112, 81 (2013).

6. S. Liu, H. Liu, Q. Q. Shi, Z. Wang, Y. Xu. Nanosci. Nanotech. Lett. 6, 268 (2014).

7. J. Xu, L. Li, C. S. Guo, Y. Zhang, W. Meng. Appl. Catal. B-environ. 130, 285 (2013).

8. M. Sheng, L, Gu, R. Kontic, Y. Zhou, K. Zheng, G. Chen, X. Mo, G. R. Patzke. Sensor Actuat. B-chem. 166, 642 (2012).

9. S. Kagaya, Y. Araki, N. Hirai, K. Hasegawa. Talanta 67, 90 (2005)

10. B. S. Naidu, B. Vishwanadh, V. Sudarsan, R. K. Vatsa. Dalton. Trans. 41, 3194 (2012).

11. C. Pan, Y. F. Zhu. J. Mater. Chem. 21, 4235 (2011).

12. S.L. Lee, S. W. Yong, K. O. Hartini. Asian J. Chem. 25, 7205 (2013).

13. J. Geng, W. H. Hou, Y. N. Lv, J. J. Zhu, H. Y. Chen. Inorg. Chem. 44, 8503 (2005).

14. F. Xue, H. Li, Y. Zhu, S. Xiong, X. Zhang, T. Wang, X. Liang, Y. T. Qian. J. Solid State Chem. 182, 1396 (2009).

15. M. Yang, N. K. Shrestha, R. Hahn, P. Schmuki. Electrochem. Solid State Lett. 13, C5 (2010).

16. Y. F. Liu, X. G. Ma, X. Yi, Y. F. Zhu. Acta Phys. Chim. Sin. 28, 654 (2012).

17. Y. Y. Zhu, Y. F. Liu, Y. H. Lu, H. Wang, Q. Ling, Y. F. Zhu. Acta Phys-Chim. Sin. 29, 576 (2013).

18. L. Wang, J. Tang, H. Yin. Asian J. Chem. 25, 2146 (2013).

19. G. Li, Y. Ding, Y. Zhang, Z. Lu, H. Sun, R. Chen. J. Colloid. Interface Sci. 363, 497 (2011).

20. L. Li, J. Xu, C. Guo, Y. Zhang. Front Env. Sci. Eng. 7, 382 (2013).

21. Y. F. Lin, H. W. Chang, S. Y. Lu, C. W. Liu. J. Phys. Chem. C 111, 18538 (2007).

22. M. H. Fulekar, A. Singh, D. P. Dutta, M. Roy, A. Ballal, A. K. Tyagi. Rsc Adv. 4, 10097 (2014).

23. Y. Wang, X. Guan, L. Li, G. Li. Crystengcomm 14, 7907 (2012).

24. Y. He, J. Wang, L. Guo, X. An, Y. Lv, Y. Liu, W. Fa. J. Syn. Crystals 41, 1410 (2012). 